\title{
A PESQUISA EM ENSINO DE QUÍMICA COMO ÁREA ESTRATÉGICA PARA O DESENVOLVIMENTO DA QUÍMICA
}

\author{
Wildson Luiz Pereira dos Santos* \\ Instituto de Química, Universidade de Brasília, Campus Darcy Ribeiro, 70904-970 Brasília - DF, Brasil \\ Paulo Alves Porto \\ Departamento de Química Fundamental, Instituto de Química, Universidade de São Paulo, São Paulo - SP, Brasil
}

Recebido em 15/7/13; aceito em 25/9/13; publicado na web em 16/10/13

\begin{abstract}
RESEARCH IN CHEMICAL EDUCATION AS A STRATEGIC AREA FOR THE DEVELOPMENT OF CHEMISTRY. This paper presents an overview of the development of chemical education as a research area and some of its contributions to society. Although science education is a relatively recent area of research, it went through an expressive development in the last decades. As in the whole world, in Brazil also such development is attested by the expressive number of scientific societies, specialized journals, and meetings with growing attendance in the areas of science education in general and chemical education in particular. Following are the main contributions of research in science education related to chemistry teaching: adoption of teaching-learning principles in chemistry education; contextualization of chemical knowledge; interdisciplinary approach to chemistry teaching; use of the history of science for the definition of contents and for the design of curricula and teaching tools; development of specific disciplines for the initial and in-service training of chemistry teachers; publication of innovative chemistry textbooks by university-based research groups; elaboration of official guidelines for high-school level; and evaluation of chemistry textbooks to be distributed to high-school students by the Brazilian government. In spite of a positive impact of such initiatives, science education in Brazil still faces many problems, as indicated by poor results in international evaluations (such as the Program for International Student Assessment). However, changes in such a scenario depend less on the research in chemical education than on the much-needed governmental initiatives aiming at the improvement of both attractiveness of teaching career and structural conditions of public schools. In conclusion, new government investments in education are necessary for continuing the development of chemistry; moreover, scientific societies and decision makers in educational policies should take into consideration the contributions originated from the chemical education research area.
\end{abstract}

Keywords: chemical education; research in chemical education; chemical education in Brazil.

\section{INTRODUÇÃO}

Dentro da perspectiva de refletir sobre a atualidade e os desafios da situação da Química, em resposta à proposta da Comissão constituída pela Diretoria e Conselho Consultivo da SBQ para a realização do "Censo da Química no País", o presente artigo objetiva apresentar contribuições da pesquisa no Ensino de Química para o desenvolvimento da Química. Nesse sentido, este artigo se configura também em um position paper que busca sintetizar as principais contribuições da área de Pesquisa em Ensino de Química no tocante ao tema "Educação em Química: da educação básica à pós-graduação", destacado pela referida Comissão em seu position paper de 2012. Esse artigo, intitulado "Química sem fronteiras", assinalava a presença de desafios globais para a Química, a serem resolvidos em escala nacional, regional, estadual e/ou municipal. ${ }^{2}$ No presente artigo, delineia-se brevemente uma perspectiva histórica dos desafios enfrentados pela área de Ensino de Química em todo o mundo, mas trazendo o foco para os desafios do presente, e como vêm sendo tratados no contexto brasileiro.

Não há desenvolvimento científico e tecnológico de uma nação sem que se tenha um sistema educacional sólido para a educação básica. A pesquisa em educação em Química se constitui em área estratégica que se consolidou no Brasil e na qual a Divisão de Ensino de Química da Sociedade Brasileira de Química (SBQ) tem larga atuação. As investigações conduzidas por pesquisadores dessa área têm contribuído de forma significativa nos processos de formação de professores, de discussão e elaboração de políticas públicas e no desenvolvimento de propostas de ensino para a escola da educação básica.

\footnotetext{
*e-mail: wildson@unb.br
}

No presente artigo são apresentadas sínteses de contribuições centrais da pesquisa da área de Ensino de Química para a educação básica, que têm sido veiculadas no âmbito da Divisão de Ensino de Química da SBQ.

\section{A PESQUISA NO ENSINO DE CIÊNCIAS E O DESENVOLVIMENTO CIENTÍFICO}

O desenvolvimento científico e tecnológico dos países sempre esteve atrelado a investimentos maciços na pesquisa científica. Todavia, está claro que esse investimento só prospera se for acompanhado de investimentos em educação, que deve se iniciar na educação básica.

Um exemplo dessa simbiose, percebida por países considerados desenvolvidos, está no surgimento da pesquisa em Ensino de Ciências. Essa área de pesquisa, que está consolidada no mundo inteiro, teve como um de seus marcos inaugurais justamente um fato sócio-histórico ocorrido em plena Guerra Fria: o lançamento do primeiro satélite artificial soviético, o Sputnik, que ilustra a relação estreita entre desenvolvimento científico e educação. ${ }^{3} \mathrm{O}$ lançamento daquele satélite levou o governo dos Estados Unidos a tomar uma posição firme de investimento na educação básica para estimular a formação de cientistas no país, a fim de gerar massa crítica suficiente para dar continuidade aos projetos de interesse nacional em ciência que viessem a colocar a nação na frente da corrida armamentista. Havia uma constatação do desinteresse dos jovens pelas áreas de ciências, e uma falta de novos pesquisadores que atendessem a crescente demanda das necessidades estabelecidas pelo governo.

Naquela época, foi efetuado um investimento maciço em projetos educacionais, os quais passaram a ser produzidos por cientistas renomados de todas as áreas científicas. ${ }^{3}$ Tais projetos receberam 
contribuições de equipes multidisciplinares, compostas também por psicólogos que participaram de grandes conferências nos Estados Unidos. ${ }^{4}$ Como fruto desses investimentos, foram desenvolvidos pelos cientistas ilustres, sob a orientação teórica dos princípios de teorias de ensino-aprendizagem, materiais didáticos para a educação básica em ciências, que deram uma nova dinâmica ao ensino escolar das disciplinas dessa área. Foi assim que foram produzidos, entre outros: na Física, o projeto Physical Science Study Commitee -(PSSC); na Biologia, o material Biological Science Curriculum Study (BSCS); na Química, os projetos Chemical Bond Approach (CBA) e Chemical Education Material Study (ChemStudy); e, na Matemática, o Science Mathematics Study Group (SMSG). ${ }^{3}$ A orientação metodológica desses materiais foi marcada pela influência de teorias do campo da Psicologia, que foram promovidas em grandes conferências, destacando-se as contribuições de Bruner e Piaget. ${ }^{3}$ Isso levou à proposição de um método de ensino que caracterizou a orientação de todos aqueles projetos educacionais: o ensino pelo método da descoberta. ${ }^{5}$

Esses projetos fizeram sucesso nos Estados Unidos, e o seu modelo foi copiado em outros países, como no projeto inglês Nuffield, e disseminado em projetos patrocinados pela Unesco. ${ }^{3}$ No Brasil, esses materiais foram traduzidos com recursos do convênio MEC/USAID, e foram adotados em Escolas de Aplicação de várias universidades brasileiras, em escolas preparatórias de Academias Militares e em Escolas Estaduais de Cursos Científicos.

Amplamente utilizados em vários países, esses materiais provocaram mudanças no estilo de ensino de ciências. Uma delas foi o propalado método da descoberta. Esse método encorajou a substituição de experimentos ilustrativos de fenômenos por experimentos investigativos, nos quais os estudantes eram estimulados a elaborar modelos explicativos, em vez de simplesmente repetirem conclusões já esperadas pela teoria previamente estudada. Outra mudança provocada foi a substituição de livros descritivos da ciência por livros explicativos de modelos científicos. Em vez de textos centrados na repetição de teorias, passou-se a produzir textos que promovessem a compreensão de modelos científicos centrais de cada ciência. A prioridade era estimular o pensamento científico e a criatividade, e não a mera repetição.

Ao final da década de 1960, vários projetos educacionais foram financiados para avaliar o impacto daqueles materiais sobre a educação científica. Assim, no mundo inteiro surgiram grupos de pesquisas de caráter multidisciplinar, que se sentiram desafiados a produzir e avaliar materiais didáticos de ensino de ciências. ${ }^{3,5}$

Todo esse contexto favoreceu a emergência do campo de pesquisa em Educação em Ciências, que Cachapuz et al. denominaram de Didática das Ciências, ${ }^{5}$ e que é mais comumente referido no Brasil como Ensino de Ciências. Segundo Cachapuz et al., o surgimento desse campo se deu em função de dois fatores: a crescente importância concedida à educação científica, e o fracasso escolar do ensino de ciências, com o elevado desinteresse de estudantes por essa área. ${ }^{5}$ Isso constituiu uma problemática de investigação, gerando pesquisas a respeito dos problemas observados nos processos de ensino e aprendizagem das ciências, o que culminou com a emergência da Didática das Ciências. ${ }^{5}$

Essa área se consolidou internacionalmente, com o surgimento vertiginoso e consolidação de periódicos internacionais da área (por exemplo, Science Education, Journal of Research in Science Teaching, International Journal of Science Education, Science and Technological Education, Enzeñanza de las Ciencias), publicações de dissertações e teses, multiplicação de congressos científicos e de sociedades científicas dedicadas à área. ${ }^{5}$ Essa constatação é confirmada por uma infinidade de trabalhos de revisão na área, além da publicação de Handbooks sobre pesquisas no Ensino de Ciências que são amplamente referenciados com dezenas de citações feitas por Cachapuz et al..$^{5}$

Para Cachapuz et al.,5 "a Didática das Ciências constitui, em particular, um campo específico de investigação a partir do momento em que as problemáticas que lhe estão subjacentes são o ensino $e$ a aprendizagem das ciências". Para Schnetzler, ${ }^{6}$ a identidade da pesquisa do Ensino de Ciências:

"é marcada pela especificidade do conhecimento científico, que está na raiz dos problemas de ensino e de aprendizagem investigados, implicando pesquisas sobre métodos didáticos mais adequados ao ensino daquele conhecimento e investigações sobre processos que melhor dêem conta de necessárias reelaborações conceituais ou transposições didáticas para o ensino daquele conhecimento em contextos escolares determinados. Isso significa que o ensino de ciências/química implica a transformação do conhecimento científico/químico em conhecimento escolar, configurando a necessidade de criação de um novo campo de estudo e investigação, no qual questões centrais sobre o que, como e porque ensinar ciências/química constituem o cerne das pesquisas."

Para o caso particular de Química, Schnetzler ${ }^{6}$ destaca que: $^{-}$

\begin{abstract}
"a pesquisa em ensino de química dependia da divulgação da sua capacidade de resolver problemas que não poderiam ser resolvidos pelas outras áreas da química, pois o domínio do conhecimento químico é uma condição necessária, mas não é suficiente para o desenvolvimento da área. Nós, pesquisadores em ensino, nos envolvemos com interações entre pessoas (alunos e professores) e com a dinâmica do conhecimento nas aulas de química. Assim, precisamos recorrer a contribuições teóricas da filosofia, da psicologia, da sociologia, da antropologia, etc."
\end{abstract}

Nardi, ${ }^{7}$ em sua pesquisa sobre as características da área de Ensino de Ciências no Brasil, na qual entrevistou 24 pesquisadores da área de Ensino de Ciências indicados pelos seus pares, apresenta como principais características identificadas para a área:

"I) a inter ou multidisciplinaridade da área; II) o papel dos conhecimentos específicos nas atividades de pesquisa e docência; III) seu caráter de pesquisa aplicada ou de pesquisa \& desenvolvimento; $e$, em função disso, sua classificação como Ciências Humanas Aplicadas. (...) IV) uma concepção e avaliação sobre a pesquisa mais próxima de modelos advindos do exterior, em função de suas formações acadêmicas. (...) V) a presença da História e Filosofia da Ciência na pesquisa em ensino de Ciências; VI) a diversidade de perspectivas em termos de objetos de pesquisa, referenciais teóricos, referenciais metodológicos e outros aspectos relevantes e VII) a tensão (antiga) para definir o lócus da pesquisa nessa área: mais próximo da área de 'conteúdos'e de seus referenciais epistemológicos ou histórico-filosóficos ou mais próximo dos aportes que marcam a área da 'Educação'(Psicologia, Sociologia, etc.)."

\section{A PESQUISA EM ENSINO DE QUÍMICA NO BRASIL}

Segundo Krasilchik, ${ }^{3}$ no Brasil, desde a década de 1950, havia um movimento de renovação do ensino de ciências, o qual tomou um impulso maior na década de 1960, com a tradução dos projetos estadunidenses de ensino de ciências. A introdução desses materiais 
levou à criação de Centros de Ciências em vários Estados brasileiros, os quais tiveram um papel importante no treinamento de professores para a adoção dos materiais. Esse processou propiciou o surgimento de uma comunidade de pesquisadores de Física, Química e Biologia interessados em participar de estudos multidisciplinares sobre problemas relacionados à aprendizagem da Ciência. ${ }^{8,9} \mathrm{O}$ histórico do ensino de Ciências no Brasil foi bem detalhado por Almeida Júnior, ${ }^{10}$ e a constituição da área de Pesquisa em Ensino de Ciências está bem documentada por diversos autores. ${ }^{3,6,7,11-16}$

Como indicadores da produção científica nessa área, podemos apontar: os dados coletados por Megid Neto, ${ }^{12}$ que identificou 1071 dissertações e teses defendidas no campo da educação em Ciências entre 1972 e 2003; os dados descritos por Nardi $^{7}$ a respeito da criação de Secretarias e Divisões de Ensino em sociedades científicas importantes, como a Sociedade Brasileira de Física (SBF), Sociedade Brasileira de Química (SBQ) e a Sociedade Brasileira de Astronomia (SBA); a criação de sociedades específicas sobre o ensino e a pesquisa no ensino de Ciências, como a Sociedade Brasileira de Ensino de Biologia (SBEnBio) e Associação Brasileira de Pesquisa em Educação em Ciências (Abrapec); a realização de eventos nacionais específicos relacionados à educação em Ciências, que hoje já totalizam mais de dez eventos regulares; a publicação de periódicos específicos, que em 2012 somavam uma dezena de revistas nacionais classificadas nos estratos A1 e A2 do Qualis da Capes da área de Ensino; e a constituição de grupos de pesquisas em Programa de Pós-Graduação em Ensino de Ciências, que em 2013 totalizavam 66 Programas de Ensino de Ciências registrados na Capes, além de dezenas de núcleos que compõem Linhas de Pesquisa em Ensino de Ciências vinculados a Programas de PósGraduação em Educação.

O crescimento vertiginoso da área é demonstrado pelo aumento do número de trabalhos apresentados em congressos científicos. Em 1997, o primeiro Encontro Nacional de Pesquisadores em Educação em Ciências (ENPEC), congresso organizado pela Abrapec, contou com a participação de 135 pesquisadores, com a apresentação de 128 trabalhos; já no VII Enpec, realizado em 2011, foram apresentados 723 trabalhos. Schnetzler ${ }^{6}$ fez um levantamento do número de trabalhos apresentados nas sessões de Ensino de Química das Reuniões Anuais da SBQ, verificando expressivo crescimento: de cinco trabalhos, apresentados em 1978, para 108 trabalhos no ano de 2001. No seu levantamento, Schnetzler aponta que desde o primeiro número da revista Química Nova até 2001 foram publicados 173 artigos na seção de educação. Entre 2002 e 2012, foram publicados 255 artigos na seção de educação da revista Química Nova. Devese destacar que a Sessão de Painéis de Ensino de Química da $36^{\text {a }}$ Reunião Anual da SBQ, em 2013, teve 158 trabalhos aprovados, se constituindo na terceira maior sessão em número de trabalhos aprovados, dentre as 18 sessões de trabalhos em que se dividiu a Reunião.

Outro dado importante do crescimento e do impacto da área de Ensino de Química pode ser avaliado pelos resultados alcançados nos Encontros Nacionais de Ensino de Química (ENEQs). Schnetzler, ${ }^{14}$ em sua palestra comemorativa dos 25 anos de realização de ENEQs, afirmou que o primeiro encontro, realizado em 1982 na Universidade Estadual de Campinas (Unicamp), teve a participação de 253 pessoas. Já o mais recente ENEQ, realizado na Universidade Federal da Bahia (UFBA) em Salvador, no ano de 2012, teve a participação de quase 2 mil pessoas, segundo os organizadores.

O crescimento da comunidade é constatado também pelo número crescente de publicações de artigos científicos. Exemplo dessa evolução está nas publicações da revista Química Nova na Escola (QNEsc). Mortimer ${ }^{17}$ destaca a consolidação dessa revista em seu artigo sobre os dez anos de publicação de QNEsc:
"Esse nosso esforço inicial foi altamente recompensado e QNEsc completa 10 anos como uma revista definitivamente incorporada à cena educacional brasileira, com ampla repercussão não só entre os pesquisadores da área de Educação em Ciências mas em toda a comunidade de químicos reunidos na $S B Q$.”

Com o objetivo de atender ao público específico de professores da educação básica, a revista foi moldada com um formato próprio que tem a sua própria identidade. O seu corpo de assessores, que envolve químicos e pesquisadores da área de ensino, faz com que os seus artigos apresentem contribuições significativas em termos de conhecimento químico e de adequação educacional. O seu modelo inspirou a publicação da revista Educació Química da Sociedade Catalã de Química. Pesquisadores portugueses de educação química adotam a Química Nova na Escola como referência em cursos de formação de professores, bem como em suas pesquisas. A Sociedade Brasileira de Física também criou uma revista com formato semelhante ao da Química Nova na Escola, a revista Física na Escola.

O relato de um leitor de Química Nova na Escola demonstra o impacto que a mesma possui no sistema educacional. O seu relato foi publicado em artigo de sua autoria, 17 anos de Química Nova na Escola: Notas de Alguém que a Leu como Estudante no Ensino Médio e no Ensino Superior com Aspirações à Docência..$^{18}$ Afirma o distinto leitor:

"É necessário destacar que a revista se propõe a função de subsidiar o trabalho, a formação e a atualização de professores e efetivamente tem servido para isso, no mínimo, ao longo da minha história. Tive contato com artigos publicados na revista durante o curso médio, estudei na graduação artigos publicados lá e sempre ouvi de meus professores o nome da revista como sugestão de referencial para trabalho em sala de aula". ${ }^{18}$

\section{CONTRIBUIÇÕES DA PESQUISA EM ENSINO DE QUÍMICA}

As contribuições da pesquisa em Ensino de Química estão expressas nos resultados de dissertações e teses e nos artigos publicados em livros, periódicos e anais de congressos da área. Para sistematizar muitas dessas contribuições, apresentamos aqui algumas sínteses que foram publicadas em duas obras da área: Educação Química no Brasil: memórias, políticas e tendências ${ }^{19}$ e Ensino de Química: visões e reflexões. ${ }^{20} \mathrm{O}$ primeiro livro reúne contribuições apresentadas em conferências e comunicações em mesas redondas durante a realização do XII ENEQ, e o segundo livro apresenta contribuições de comunicações efetuadas durante o Workshop "Passado, presente e futuro do Ensino de Química no Brasil". Cientes de que esta sistematização é reduzida e que não incorpora importantes outras contribuições, o nosso trabalho consiste em destacar pontos que têm favorecido a compreensão da Ciência.

Schnetzler ${ }^{16}$ destaca contribuições na trajetória da pesquisa em Ensino de Química nos seguintes temas: a) processo de ensino-aprendizagem em Química; b) abordagem do cotidiano e contextualização de conhecimentos químicos; c) contribuições para o ensino médio e para o ensino superior; d) desafios para melhorar a formação docente em Química. Maldaner ${ }^{21}$ também destaca a importância do processo de formação do educador químico.

Marcondes ${ }^{22}$ destaca três avanços importantes na área: a) contribuições da Pós-Graduação para reflexões e ações na melhoria do ensino de Ciências; b) produção de livros que têm subsidiado a formação inicial e continuada de professores, bem como a produção 
de livros didáticos inovadores; c) participação de grupos de Ensino de Química nas políticas públicas educacionais.

$Z_{\text {Zanon }}{ }^{23}$ apresenta como tendências curriculares atuais no ensino de Ciências/Química a contextualização e a interdisciplinaridade. No caminho da interdisciplinaridade, Chassot $^{24}$ propõe um ensino de Química menos disciplinar e mais transdisciplinar. Em seu texto, destaca que a história da ciência pode ser catalisadora de propostas transdisciplinares. ${ }^{24}$

Certamente, muitas outras proposições são encontradas nas obras citadas e em diversas outras publicações da área, mas, a partir das aqui mencionadas, podemos levantar tópicos centrais como contribuições da área de Ensino de Química para o avanço da Química na sociedade. Esses tópicos estão sintetizados nas seções a seguir.

\section{Adoção de princípios do processo de ensino-aprendizagem ao Ensino de Química}

Schnetzler ${ }^{16}$ aponta que as pesquisas na área começaram com a crença na aprendizagem por descoberta, para depois passar para orientações construtivistas e para investigações sobre concepções alternativas de alunos e processos de mudança conceitual. As pesquisas com orientações construtivistas contribuíram para um maior entendimento do processo educativo em sala de aula, do processo de aprendizagem do aluno e para o desenvolvimento de materiais de ensino. No Brasil, vários projetos curriculares foram desenvolvidos sob essas orientações como o Proquim e o GEPEQ, dentre outros..$^{25}$

Posteriormente, estudos na perspectiva histórico-cultural de Vygostki passaram a orientar pesquisas no ensino de ciências no sentido de atribuir maior atenção às interações de sala de aula e ao papel da linguagem. Várias pesquisas nesse campo redirecionaram o olhar para as aulas de Química e chamaram a atenção para a importância da linguagem científica para o aprendizado. ${ }^{26,27}$ Mortimer destaca que essa aprendizagem ocorre por meio de uma apropriação gradual de significados, em que há possibilidade de construção de hibridizações entre as linguagens científicas e cotidianas. ${ }^{27}$ Resultados dessas pesquisas têm contribuído no processo de formação de professores.

\section{Contextualização de conhecimentos químicos}

Em trabalho recente, Wartha et al. ${ }^{28}$ mostraram que o termo "contextualização" tem sido bastante utilizado no âmbito do Ensino de Química, embora o termo venha sendo interpretado de várias maneiras diferentes. Sumarizando os resultados de outros autores, Wartha et al. observam que a contextualização pode ser interpretada de maneira mais simplista por alguns educadores em Química, significando apenas a explicação científica de fatos e processos pertencentes ao cotidiano dos alunos. Uma concepção um pouco mais elaborada propõe a contextualização como estratégia ou metodologia de ensino, pela qual o professor propõe a aproximação entre os fatos e processos da realidade social dos alunos e os conhecimentos científicos, de modo que os alunos compreendam que estes podem dar significado àqueles. Uma concepção mais complexa entende a contextualização como princípio norteador para o ensino de ciências, na perspectiva de uma educação transformadora, como no modelo freireano de problematização, organização do conhecimento e aplicação do conhecimento, como discute Santos. ${ }^{29}$

A educação nessa perspectiva tem como propósito central a formação para a cidadania ${ }^{30}$ e nela se inserem propostas com enfoque nas inter-relações Ciência-Tecnologia-Sociedade (CTS). ${ }^{31}$ Todos esses estudos relativos à contextualização contribuíram para o desenvolvimento de materiais de ensino com enfoque em temas do cotidiano, ${ }^{32}$ temas sociais ${ }^{33}$ ou do que tem sido denominado de situações de estudo. ${ }^{34}$ De certa maneira, essas discussões têm provocado mudanças nos livros didáticos que, até os anos 1970, eram considerados livros distantes da vida do aluno, e que hoje buscam de alguma forma vincular a presença da Química a nossas vidas.

\section{Interdisciplinaridade e história da ciência}

No dia a dia de seu trabalho, é comum os professores de ciências em geral, e de Química em particular, frustrarem-se com as dificuldades que os alunos apresentam em compreender os conteúdos ensinados. As dificuldades são tantas e tão generalizadas que o pesquisador Michael Matthews ${ }^{35}$ chega a falar de um "mar de falta de significação" no ensino de ciências. O desafio que se apresenta para todos os educadores em química consiste em como lidar com esse "mar de falta de significação", de modo a poder ajudar os alunos e o público em geral a entenderem, afinal, do que se trata a química. Um dos possíveis caminhos envolve a aproximação entre a História da Ciência e o Ensino de Química. A História da Ciência pode ajudar a compreender aspectos da complexidade do conhecimento químico e de seu processo de construção, auxiliando na compreensão de algumas das dificuldades enfrentadas pelos estudantes, e assim oferecendo contribuições para a melhoria da aprendizagem. A análise do processo histórico do desenvolvimento da ciência pode auxiliar o estudante a dar significado ao conhecimento químico, ao vislumbrar as questões que motivaram a proposição de conceitos e do olhar característico que o químico lança sobre a realidade. Entretanto, a aproximação entre duas áreas de conhecimento distintas, com características, objetivos e metodologias próprias, é sempre um caminho difícil. Por isso, a área de ensino tem se beneficiado também do crescimento, no Brasil, dos programas de pós-graduação em História da Ciência, com o consequente aumento do número de historiadores da química com formação especializada e atualizada. Se os programas de pós-graduação específicos em História da Ciência surgiram no Brasil apenas na década de 1990, atualmente existem vários programas que reúnem pesquisadores das áreas de História, Filosofia e Ensino de Química, em profícua interação.

O diálogo com diferentes áreas do conhecimento é característico da História da Ciência, o que pode auxiliar no desenvolvimento de abordagens interdisciplinares no âmbito escolar. A interdisciplinaridade no ensino tem sido recomendada nas mais recentes reformas educacionais e parece ser um dos ideais mais difíceis de serem colocados em prática, mas diversos trabalhos têm demonstrado como isso pode ser feito em sala de aula, como aponta Zanon. ${ }^{23} \mathrm{Um}$ caminho possível consiste na abordagem de estudos de caso históricos, conforme propõe Porto. ${ }^{36} \mathrm{~A}$ partir desses estudos, pode-se discutir conteúdos das ciências da Natureza e seus respectivos processos de construção, considerando ainda o contexto histórico e as interações entre ciência e sociedade. ${ }^{24}$

\section{Formação docente em Química}

Schnetzler ${ }^{16}$ aponta diversos resultados de dissertações e teses que desenvolveram pesquisas sobre a formação de professores de Química. Essas pesquisas têm apontado contribuições significativas para mudanças curriculares nos cursos de licenciatura em Química, destacando a importância de esses cursos incorporarem disciplinas específicas de Ensino de Química. Mais de uma dezena desses estudos foi publicada na revista Química Nova, na seção Educação. ${ }^{37}$ Duas importantes contribuições nesse sentido estão sintetizadas nas obras A Formação Inicial e Continuada de Professores de Química - Professores/Pesquisadores ${ }^{38}$ e Formação Superior em Química no Brasil-Práticas e Fundamentos Curriculares ${ }^{39}$ e pode-se citar ainda quatro outras contribuições sobre formação de professores na obra Educação Química no Brasil: memórias, políticas e tendências. ${ }^{40}$ 
Maldaner, ${ }^{21}$ em sua palestra A Pós-Graduação e a Formação do Educador Químico, demonstra a necessidade atual da presença de educadores químicos nas licenciaturas em Química, concluindo que:

"É essencial, ainda, que a fortificação de uma comunidade de Educação Química seja constituída e defendida, também, pelas melhores cabeças químicas deste país. Formar melhor as novas gerações no conhecimento químico proporciona novas vocações químicas, o que poderá permitir que o Brasil passe a ser mais capaz na geração da ciência e da tecnologia química, cuja dependência externa é quase total no que se refere à Nova Química."

Deve-se destacar, ainda, que os resultados das pesquisas em Ensino de Química têm contribuído de forma significativa na produção de livros para a formação de professores, muitos dos quais têm sido publicados na Coleção Educação em Química da Editora Unijuí, que até 2013 já publicou 12 títulos.

\section{Produção de livros didáticos inovadores}

A história da área de Ensino de Química, tanto em nível internacional quanto nacional, esteve relacionada ao processo de produção de livros didáticos inovadores, conforme histórico acima apresentado. Mortimer, ${ }^{41}$ em sua pesquisa, apresenta um estudo histórico sobre livros didáticos de Química brasileiros até 1987, destacando como os períodos marcados por debates sobre o ensino de Química contribuíram para a construção de propostas inovadoras. Mortimer e Santos ${ }^{42}$ atualizaram o histórico dos livros didáticos até 2007 e concluíram que "o surgimento dos atuais livros didáticos diferenciados acontece no cerne de um movimento de expansão de uma comunidade de pesquisadores, educadores e professores de Química que podem gerar tendências inovadoras mais consistentes e mais persistentes no tempo".

Essa constatação demonstra mais uma contribuição da pesquisa em Ensino de Química. Deve-se destacar ainda que o processo de produção de materiais didáticos inovadores esteve associado à constituição de diversos grupos de pesquisa. ${ }^{42}$ Nesse sentido, uma característica central da pesquisa em Ensino de Química é a sua produção de materiais que se aplicam diretamente na escola e que produzem impactos, contribuindo para o estabelecimento de mudanças no processo de ensino-aprendizagem, de forma que os estudantes adquiram uma nova visão da Química e do seu papel na sociedade.

\section{Participação de grupos de Ensino de Química em políticas públicas educacionais}

Outra contribuição de destaque oferecida pela comunidade de pesquisadores em Ensino de Química tem sido na formulação de políticas públicas. Nesse sentido, pode-se destacar a participação de pesquisadores da área na elaboração dos Parâmetros Curriculares Nacionais para o Ensino Médio (PCNEM), bem como das Orientações Educacionais Complementares aos Parâmetros Curriculares Nacionais (conhecidas como $\mathrm{PCN}+$ ) ${ }^{43}$ documentos que redefiniram os objetivos e as abordagens para o ensino de Química em nível médio, a partir dos caminhos apontados pela nova Lei de Diretrizes e Bases da Educação Nacional, de 1996. Os PCNEM foram objeto de uma revisão crítica, a cargo de outra equipe de pesquisadores, também participantes da Divisão de Ensino de Química da SBQ, que resultou na publicação das Orientações Curriculares do Ensino Médio, em $2004 .{ }^{43}$ Pode-se citar, ainda, a participação de grupos de pesquisa em Ensino de Química no processo de análise de livro didáticos do Programa Nacional de Livro Didático. ${ }^{44}$
Também em diversos Estados, os pesquisadores têm participado da elaboração de propostas curriculares para o ensino de Química. Podemos citar como exemplo a proposta curricular do Estado de Minas Gerais. No Estado de São Paulo, pesquisadores da área de Ensino de Química participaram não apenas da formulação da proposta curricular, como também da elaboração de material didático dirigido aos alunos, e de orientações aos professores de química da rede estadual.

Enfim, como apontam Abreu e Lopes ${ }^{43}$ em seus estudos sobre a Comunidade Disciplinar de Ensino de Química na Produção de Políticas de Currículo:

"os discursos mais valorizados elou reconhecidos pela comunidade disciplinar de ensino de Química, por intermédio de seus pesquisadores, colaboraram para a construção de sentidos e de significados importantes, capazes de influenciar a produção de políticas de currículo, seja pela divulgação de seus valores e visões de mundo, seja pela associação a outros discursos que circulam na sociedade."

\section{CONSIDERAÇÕES FINAIS}

O mundo mudou bastante nas últimas décadas e a pesquisa em Ensino de Química tem sido fundamental para enfrentar os problemas relativos ao ensino dessa disciplina, que são característicos destes tempos de mudanças tão rápidas e profundas. No caso brasileiro, não é difícil diagnosticar os precários resultados da educação em ciências entre a população em geral. Seria falacioso atribuir esses maus resultados às tendências recentes para o Ensino de Ciências, especialmente àquelas resultantes das pesquisas acadêmicas na área - tal argumento apenas desvia a atenção dos verdadeiros problemas da educação nacional, que passam principalmente pela desvalorização do trabalho docente e pela precariedade das condições de trabalho dos professores nas escolas. Enquanto a educação não for encarada como prioridade de fato, e não for objeto de uma política de Estado, nenhuma reforma curricular poderá alcançar todos os objetivos pretendidos.

O editorial de Química Nova na Escola, vol. 32, n 3, de 2010, apresenta uma síntese do que a comunidade de pesquisadores da área de Ensino de Química, reunidos em Brasília, por ocasião do XV Encontro Nacional de Ensino de Química, propunha em termos de política pública em sua "Carta aos Candidatos à Presidência da República do Brasil”, publicada naquele número:

"Três conjuntos de sugestões foram apresentados e podem ser resumidos na valorização das escolas, do magistério e da formação de professores nas licenciaturas. No primeiro conjunto, além das questões estruturais, defende-se a integralidade da escola para alunos, a necessidade de redução da quantidade de alunos por sala e a implementação de salas-ambiente como meio preferencial para desenvolver as ações de ensino. Sobre a valorização do magistério, indica-se que a escola deve ser integral também para o professor, com horas previstas para planejamento de atividades, atendimento extraclasse aos alunos e em correções de avaliações, sem deixar de mencionar piso salarial e plano de carreira atraentes. No quesito formação de professores, defende-se a criação de instrumentos que permitam maior aproximação dos cursos de formação e seus profissionais com a Educação Básica, com efetiva participação do Estado para viabilizar essa aproximação."45

Mesmo diante da falta de políticas públicas eficientes em torno desses três conjuntos de sugestões, a comunidade de pesquisadores 
em Ensino de Química tem se mostrado atuante e produzido resultados muito relevantes. As mais recentes diretrizes curriculares, tanto Estaduais como nacionais, deram uma identidade ao Ensino Médio e apontaram caminhos que podem ser seguidos por professores de Química em todo o país, respeitando as especificidades regionais. Para capacitar os professores ao exercício desse novo papel, os cursos de formação inicial e continuada nas Universidades têm se beneficiado da presença de grupos de pesquisa em Ensino de Química, os quais têm aproximado da prática docente as contribuições da pesquisa. A elaboração, por esses grupos de pesquisa, de materiais didáticos, e sua participação na avaliação de livros didáticos promovida pelo Programa Nacional do Livro Didático, tem propiciado um expressivo ganho na qualidade desses recursos tão utilizados por professores e alunos. É importante destacar o papel dos Programas de PósGraduação, no âmbito dos quais se desenvolve a maior parte das pesquisas na área de Ensino de Química.

Se desejamos um desenvolvimento científico e tecnológico da Química, a meta principal deve ser investimentos maciços em educação. Os resultados desses investimentos se tornarão frutíferos na medida em que houver contribuições significativas de toda sociedade, em particular das sociedades científicas. Nesse processo, a área de Ensino de Ciências tem contribuição fundamental tanto para a educação básica, quanto para o ensino superior. Nos seus 50 anos de existência, apesar de todas as restrições a ela submetidas, impactos locais já são percebidos e eles se tornarão visíveis, na medida em que os resultados de suas pesquisas forem considerados na macropolítica educacional. Afinal, na modernidade, deve-se buscar cada vez mais o diálogo transdisciplinar para as grandes temáticas, e, por natureza, esse é o caráter da área de Ensino de Química, que tem contribuído para consolidar uma nova visão da Química na sociedade, formando cidadãos críticos.

\section{AGRADECIMENTOS}

Ao $\mathrm{CNPq}$, pelo apoio financeiro às nossas pesquisas. Aos membros da Divisão de Ensino de Química da SBQ, pelas contribuições apresentadas nos eventos de Ensino de Química, que permitiram o avanço de nossa comunidade.

\section{REFERÊNCIAS E NOTAS}

1. Editores da Revista Química Nova na Escola da Sociedade Brasileira de Química (SBQ), revista criada pela Divisão de Ensino de Química da SBQ

2. Pinto, A. C.; Zucco, C.; Galembeck, F.; de Andrade, J. B.; Vieira, P. C.; Quim. Nova 2012, 35, 2092.

3. Krasilchick, M.; O professor e o currículo das ciências, Edusp: São Paulo, 1987; Krasilchik, M. Em Inovação educacional no Brasil: problemas e perspectivas; Garcia, W. E., org.; Cortez Autores Associados: São Paulo, 1980, cap. 8; 12. Krasilchick, M.; Revista São Paulo em Perspectiva 2000, 14, 85.

4. Bruner, J. S.; O processo da educação, Ed. Nacional: São Paulo, 1966.

5. Cachapuz, A.; Praia, J.; Gil-Pérez, D.; Carrascosa, J.; Martínez-Terrades, F.; Em A necessária renovação do ensino das ciências; Cachapuz, A.; Gil-Pérez, D.; Carvalho, A. M. P. de; Praia, J.; Vilches A., orgs.; Cortez: São Paulo, 2005, cap. 8.

6. Schnetzler, R. P.; Quim. Nova 2002, 25, Supl. 1, 14.

7. Nardi, R. Em A pesquisa em ensino de ciências no Brasil: alguns recortes; Nardi, R., org.; Escrituras Editora: São Paulo, 2007, cap. 16.

8. Maldaner, O. A. Anais do XXIII Encontro de Debates do Ensino de Química, Passo Fundo, Brasil, 2003.

9. Nardi, R. Em Formar: encontros e trajetórias com professores de Ciências; Rosa, M. I. P., org.; Escrituras Editora: São Paulo, 2005, cap. 6 .
10. de Almeida Júnior, J. B.; Rev. de Ens. de Fís. 1979, 1, 45; de Almeida Júnior, J. B.; Rev. de Ens. de Fís. 1980, 2, 55.

11. Nardi, R.; Investigações em Ensino de Ciências 2005, 10, 63; Nardi, R.; Pro-posições 2005, 18, 213;

12. Megid Neto, J. Em A pesquisa em ensino de ciências no Brasil: alguns recortes; Nardi, R., org.; Escrituras Editora: São Paulo, 2007, cap. 15.

13. Delizoicov, D. Em A pesquisa em ensino de ciências no Brasil: alguns recortes; Nardi, R., org.; Escrituras Editora: São Paulo, 2007, cap. 17.

14. Schnetzler, R. P. Em Educação Química no Brasil: memórias, políticas e tendências; Rosa, M. I. P.; Rossi, A. V., orgs.; Editora Átomo: Campinas, 2008, cap. 1.

15. Schnetzler, R. P. Em Ensino de Química em foco; Santos, W. L. P.; Maldaner, O. A., orgs.; Editora Unijuí: Ijuí, 2010, cap. 2.

16. Schnetzler, R. P. Em Ensino de Química: visões e reflexões; Mól, G. S., org.; Editora Unijuí: Ijuí, 2012, cap. 3.

17. Mortimer, E. F.; Química Nova na Escola 2004, 20, 3.

18. Colen, J.; Química Nova na Escola 2012, 34, 1, 16.

19. Rosa, M. I. P.; Rossi, A. V.; Educação Química no Brasil: memórias, políticas e tendências; Editora Átomo: Campinas, 2008.

20. Mól, G. S.; Ensino de Química: visões e reflexões; Editora Unijuí: Ijuí, 2012.

21. Maldaner, O. A. Em Educação Química no Brasil: memórias, políticas e tendências; Rosa, M. I. P.; Rossi, A. V., orgs.; Editora Átomo: Campinas, 2008, cap. 13.

22. Marcondes, M. E. R. Em Ensino de Química: visões e reflexões; Mól, G. S., org.; Editora Unijuí: Ijuí, 2012, cap. 6.

23. Zanon, L. B. Em Educação Química no Brasil: memórias, políticas e tendências; Rosa, M. I. P.; Rossi, A. V., orgs.; Editora Átomo: Campinas, 2008, cap. 11.

24. Chassot, A. I. Em Educação Química no Brasil: memórias, políticas e tendências; Rosa, M. I. P.; Rossi, A. V., orgs.; Editora Átomo: Campinas, 2008, cap. 10.

25. Mortimer, E. F.; Santos, W. L. P. Em Educação Química no Brasil: memórias, políticas e tendências; Rosa, M. I. P.; Rossi, A. V., orgs.; Editora Átomo: Campinas, 2008, cap. 4.

26. Machado, A. H.; Aula de química: discurso e conhecimento; Ed. Unijuí: Ijuí, 1999. Mortimer, E. F.; Linguagem e formação de conceitos no ensino de ciências, Ed. UFMG: Belo Horizonte, 2000; Mortimer, E. F.; Scott, P.; Investigações em Ensino de Ciências 2002, 7, 283.

27. Mortimer, E. F. Em Ensino de Química em foco; Santos, W. L. P.; Maldaner, O. A., orgs.; Editora Unijuí: Ijuí, 2010, cap. 7.

28. Wartha, E. J.; Silva, E. L.; Bejarano, N. R. R. Química Nova na Escola 2013, 35, 84.

29. Santos, W. L. P.; Revista Alexandria 2008, 1, 109.

30. Santos, W. L. P.; Schnetzler, R. P.; Educação em Química: compromisso com a cidadania; Editora Unijuí: Ijuí, 1997.

31. Santos, W. L. P.; Mortimer, E. F. Ensaio: Pesq. em Educ. em Ciênc. 2000, 2, 133.

32. Lufti, M.; Cotidiano e educação em química: os aditivos em alimentos como proposta para o ensino de Química no segundo grau; Livraria Unijuí: Ijuí, 1988. Lufti, M.; Os ferrados e os cromados: produção social e apropriação privada do conhecimento químico, Ed. Unijuí: Ijuí, 1992.

33. Santos, W. L. P.; Mól, G. S.; Silva, R. R.; Castro, E. N. F.; Silva, G. S.; Matsunaga, R. T.; Farias, S. B.; Santos, S. M. O.; Dib, S. M. F.; Química Nova na Escola 2004, 20, 11.

34. Maldaner, O. A.; Zanon, L. B. Em Educação em ciências: produção de currículos e formação de professores, Moraes, R.; Mancuso, R., orgs.; Editora Unijuí: Ijuí, 2004, cap. 2.

35. Matthews, M. R.; Caderno Catarinense de Ensino de Física 1995, 12, 164.

36. Porto, P. A. Em Ensino de Química em foco; Santos, W. L. P.; Maldaner, O. A., orgs.; Editora Unijuí: Ijuí, 2010, cap. 6. 
37. Massena, E. P.; Monteiro, A. M. F. da C.; Quim. Nova 2011, 34, 1476; Mesquita, N. A. da S.; Soares, M. H. F. B.; Quim. Nova 2011, 34, 165; Vianna, J. F.; Aydos, M. C. R.; Siqueira, O. S.; Quim. Nova 1997, 20 , 213; Santos, W. L. P. dos; Gauche, R.; da Silva, R. R.; Quim. Nova 1997, 20, 675; Teixeira Júnior, J. G.; da Silva, R. M. G.; Quim. Nova 2007, 30, 1365; Galiazzi, M. do C.; Gonçalves, F. P.; Quim. Nova 2004, 27 , 326; Garcia, I. T. S.; Kruger, V.; Quim. Nova 2009, 32, 2218; Abreu, D. G. de; Campos, M. L. A. M.; Aguilar, M. B. R.; Quim. Nova 2008, 31, 688; Kasseboehmer, A. C.; Ferreira, L. H.; Quim. Nova 2008, 31, 694; Pereira, J. B.; Campos, M. L. A. M.; Nunes, S. M. T.; de Abreu, D. G.; Quim. Nova 2009, 32, 511; Maldaner, O. A.; Quim. Nova 1999, 22, 289.

38. Maldaner, O. A.; A Formação Inicial e Continuada de Professores de Química - Professores/Pesquisadores; Editora Unijuí: Ijuí, 2003.

39. Echeverría, A. R.; Zanon, L. B.; Formação Superior em Química no Brasil - Práticas e Fundamentos Curriculares; Editora Unijuí: Ijuí, 2010.

40. Rosa, M. I. P.; Carreri, A. V.; Ramos, T. A.; Em Educação Química no Brasil: memórias, políticas e tendências; Rosa, M. I. P.; Rossi, A. V., orgs.; Editora Átomo: Campinas, 2008, cap. 5; Rossi, A. V.; Ferreira, L. H.; Em Educação Química no Brasil: memórias, políticas e tendências;
Rosa, M. I. P.; Rossi, A. V., orgs.; Editora Átomo: Campinas, 2008, cap. 6; Rosa, M. I. P.; Oliveira, A. C. G.; Pavan, A. C.; Corradi, D. P.; Em Educação Química no Brasil: memórias, políticas e tendências; Rosa, M. I. P.; Rossi, A. V., orgs.; Editora Átomo: Campinas, 2008, cap. 7; Gauche, R.; Tunes, E.; Em Educação Química no Brasil: memórias, políticas e tendências; Rosa, M. I. P.; Rossi, A. V., orgs.; Editora Átomo: Campinas, 2008, cap. 8.

41. Mortimer, E. F.; Dissertação de Mestrado, Universidade Federal de Minas Gerais, Brasil, 1988.

42. Mortimer, E. F.; Santos, W. L. P.; Em Educação Química no Brasil: memórias, políticas e tendências; Rosa, M. I. P.; Rossi, A. V., orgs.; Editora Átomo: Campinas, 2008, cap. 4.

43. Abreu, R. G. de; Lopes, A. C. Em Educação Química no Brasil: memórias, políticas e tendências; Rosa, M. I. P.; Rossi, A. V., orgs.; Editora Átomo: Campinas, 2008, cap. 2.

44. Echeverria, A.; Mello, I. C.; Gauche, R. Em Educação Química no Brasil: memórias, políticas e tendências; Rosa, M. I. P.; Rossi, A. V., orgs.; Editora Átomo: Campinas, 2008, cap. 3.

45. Cangemi, J. M.; Santos, A. M.; Claro Neto, S.; Química Nova na Escola 2010, 32, 3 . 